\title{
Reflexões sobre a municipalização da segurança a partir do diagnóstico de segurança pública do município de São Gonçalo (Rio de Janeiro)
}

\author{
Reflections on the municipalization of security from the diagnosis of \\ public security of the municipality of São Gonçalo (Rio de Janeiro)
}

\author{
Antonio Rafael Barbosa \\ Gláucia Mouzinho \\ Roberto Kant de Lima \\ Edilson Marcio Silva*
}

\begin{abstract}
Resumo: Neste texto buscamos apresentar algumas reflexões sobre a pesquisa desenvolvida pelo Nufep (Núcleo Fluminense de Estudos e Pesquisas) da Universidade Federal Fluminense (UFF) que resultou no diagnóstico de segurança pública e nas diretrizes do plano municipal de segurança pública de São Gonçalo. É nosso interesse discutir o tema a partir de quatro enfoques específicos: as ações indutoras do governo federal; os processos institucionais de administração de conflitos; a importância das relações pessoais na política municipal; as representações sobre o pertencimento local e sua significação para o desenvolvimento de políticas públicas.
\end{abstract}

Palavras-chave: Segurança municipal; Políticas públicas; Administração institucional de conflitos; Conflitos de gênero; Violência doméstica

\begin{abstract}
This paper sought to present some reflections on the research developed by Nufep (Fluminense Center for Studies and Research) of the Federal Fluminense University (UFF) which resulted in the diagnosis of public security and the guidelines of the local plan of public security of São Gonçalo. It is our interest to discuss the issue from four specific approaches: the federal government's leading shares; the institutional processes for managing conflicts; the importance of personal relationships in municipal politic; and the representations on the local belonging and their significance for the development of public policies.
\end{abstract}

Key words: Municipal security; Public policy; Institutional conflict administration; Conflicts of gender; Domestic violence

* Antonio Rafael Barbosa é doutor em Antropologia - MN/Ufrj, bolsista Pro-Doc - PPGA/ UFF, pesquisador do Nufep/Ufrj, Rio de Janeiro, Brasil < antonio.rafael.barbosa@gmail.com>; Gláucia Mouzinho é doutora em Antropologia - PPGA/UFF, pesquisadora do Nufep/Ufrj, Rio de Janeiro, Brasil; Roberto Kant de Lima é pesquisador de produtividade do CNPq e da Faperj, Rio de Janeiro, Brasil; Edilson Marcio Silva é doutor em Antropologia - PPGA/UFF, pesquisador do Nufep/Ufrj, Rio de Janeiro, Brasil.

\begin{tabular}{|l|l|l|l|l|l|}
\hline Civitas & Porto Alegre & v. 8 & n. 3 & p. 386-408 & set.-dez. 2008 \\
\hline
\end{tabular}




\section{Introdução}

Neste artigo procuramos desenvolver algumas reflexões sobre o papel dos municípios na produção da segurança pública, a partir de nossa experiência de pesquisa na formulação do Diagnóstico de Segurança Pública do Município de São Gonçalo, Rio de Janeiro, como também do município de Mesquita (ainda que em segundo plano). É nosso interesse discutir o tema, inicialmente, a partir de alguns enfoques específicos. São eles: as ações indutivas do governo federal; os processos institucionais de administração de conflitos; a importância das relações pessoais na política municipal; as representações sobre o pertencimento local e sua relevância para o desenvolvimento de políticas públicas.

Inicialmente vamos apresentar algumas características gerais da pesquisa para situar o leitor diante do assunto.

\section{Breve notícia sobre o dignóstico de segurança pública de São Gonçalo}

No ano de 2007 foi firmado um contrato entre a Universidade Federal Fluminense - por meio do Núcleo Fluminense de Estudos e Pesquisas (Nufep) - e a Prefeitura Municipal de São Gonçalo para a elaboração do Diagnóstico Municipal de Segurança Pública de São Gonçalo. ${ }^{1}$ Neste diagnóstico foi prevista uma primeira etapa da pesquisa que consistia no levantamento dos dados quantitativos sobre os seguintes tópicos: características sóciodemográficas do município, oferta de serviços de infra-estrutura; ocupação de mão-de-obra; sistema educacional; sistema de saúde; violência, criminalidade e administração da justiça. ${ }^{2}$ Vale ressaltar que nesta etapa optamos por uma abordagem comparativa, buscando situar o município

\footnotetext{
${ }^{1}$ Este Diagnóstico de Segurança Pública foi elaborado com recursos da Prefeitura Municipal de São Gonçalo e da Finep (Financiadora de Estudos e Projetos - Ministério da Ciência e Tecnologia) - Projeto segurança pública e violência urbana: a descentralização de formas institucionais de administração de conflitos (2006-2008). O Nufep participou da elaboração de mais dois diagnósticos semelhantes a esse: no município de Mesquita e no município de São Pedro d'Aldeia (ambos situados no estado do Rio de Janeiro).

2 Os bancos de dados utilizados, em sua maioria, são considerados fontes secundárias (indicadores disponibilizados por distintas agências públicas sobre o município de São Gonçalo e municípios adjacentes). Entre as diversas fontes de dados utilizadas, podemos citar como as mais relevantes: IBGE - Instituto Brasileiro de Geografia e Estatística - Censo, 2000; Fundação Cide - Anuário Estatístico, 2006; Pesquisa Nacional de Saneamento Básico, 2005; CNES - Cadastro Nacional de Estabelecimentos de Saúde, Datasus - Banco de Dados do Sistema Único de Saúde; Sinan - Sistema de Informação de Agravos em Notificação; ISP - Instituto de Segurança Pública (Secretaria de Segurança Pública do Estado do Rio de Janeiro).
} 
de São Gonçalo em seu contexto regional. Assim, foram levados em conta os dados da região administrativa conhecida como Região Metropolitana, assim como os indicadores de dois outros municípios limítrofes: Niterói e Itaboraí. Outro município - Nova Iguaçu - também foi incluído em razão da semelhança de suas características com o município de São Gonçalo.

Complementando esse levantamento, uma segunda abordagem, idealizada no plano de trabalho da pesquisa, foi posta em curso. Tratava-se da aplicação de técnicas qualitativas de pesquisa - especialmente fazendo uso do instrumento da entrevista (em suas diversas modalidades), observação direta e da técnica de grupos focais (aqui, particularmente, utilizada com membros da Guarda Municipal). Se tais indicadores quantitativos - através do acompanhamento das flutuações nas séries temporais, do cruzamento de variáveis, da comparação com os dados dos outros municípios - podem apontar regularidades e contrastes expressivos em si mesmos, o recurso à pesquisa qualitativa permite, ao mesmo tempo, problematizar esses dados e complementar significativamente as informações ali sugeridas. ${ }^{3}$ Nesta etapa da pesquisa, foram entrevistados: juízes e promotores; membros do legislativo municipal; secretários e demais gestores de políticas públicas da prefeitura; representantes de associações de moradores e de associações ligadas ao comércio; membros da sociedade civil organizada; membros de conselhos comunitários; agentes da Polícia Militar, Polícia Civil; Polícia Rodoviária Federal e Guardas Municipais.

Por fim, uma terceira etapa consistiu na formulação de diretrizes para o Plano Municipal de Segurança de São Gonçalo, com a proposição de eixos, principalmente de competência municipal, a serem desenvolvidos para reduzir os indicadores de violência e criminalidade no município. A pesquisa terminou com a apresentação dos resultados da pesquisa em audiência pública no referido município e a entrega dos relatórios finais em junho de 2008 .

\section{Instrumentos programáticos e políticas públicas indutivas}

Nos últimos anos, no Brasil, temos acompanhado algumas mudanças no tratamento do tema da segurança pública por parte da administração

\footnotetext{
3 Apesquisa qualitativa ainda tem como propósito conhecer os processos de produção-e, portanto, as limitações - desses bancos de dados, especialmente os criminais. Como sabemos, os dados dos registros oficiais disponíveis sobre a incidência da criminalidade são apenas indicativos do que as instituições decidem registrar - de acordo com seus valores, procedimentos e propósitos - em um dado momento do tempo.
} 
pública, parte delas resultante das ações indutivas do governo federal nas esferas estadual e municipal. Um exemplo disso - diretamente relacionado ao nosso assunto - é a realização de diagnósticos dos problemas de segurança pública como condição prévia para que os municípios tenham acesso aos recursos do Fundo Nacional de Segurança Pública. ${ }^{4}$ Entretanto, as perspectivas teórico-metodológicas que balizam os sucessivos projetos de criação de uma Política Nacional de Segurança Pública, assim como os contextos políticos e os rearranjos institucionais presentes na conformação de tais iniciativas, geralmente não merecem o grau de explicitação que seria desejável. Sem querer (ou poder) aprofundar essa discussão neste artigo, alguns pontos, todavia, merecem ser assinalados.

Inicialmente, é necessário perceber as continuidades e rupturas entre os sucessivos planos de segurança pública propostos na esfera do governo federal. O primeiro Plano Nacional de Segurança Pública (assim intitulado), lançado no segundo governo Fernando Henrique Cardoso (FHC), no ano 2000, assinala um deslocamento significativo no que diz respeito ao tratamento do assunto até então - a segurança pública adentra a agenda de discussões para assumir um lugar central nos compromissos da União, rompendo com uma postura inercial que deixava os problemas da segurança restritos somente aos Estados e suas polícias (Azevedo e Fagundes, 2007, p. 91) e que facultava a reprodução, nas sombras, de antigas práticas policiais marcadas pela arbitrariedade, violência e autoritarismo. Por outro lado, se é, realmente, um marco decisivo, juntamente com a criação do Fundo Nacional de Segurança Pública, ${ }^{5}$ também não podemos deixar de lembrar os esforços que lhe antecedem no plano institucional e programático - no primeiro governo FHC - com a criação da Secretaria Nacional de Direitos Humanos e a formulação do primeiro Plano Nacional de Direitos Humanos, e, em 1997, com a criação da Secretaria Nacional de Segurança Pública (Senasp).

Assim, no Plano Nacional de Segurança Pública, destacam-se os seguintes pontos: a ênfase nas ações preventivas; o apoio à qualificação policial; a busca da integração cooperativa entre as instituições policiais; o estímulo à expansão das penas alternativas; a valorização do policiamento comunitário; a adequação dos mecanismos de proteção a testemunhas e vítimas de crime com a pauta dos Direitos Humanos; o controle de armas, entre outros. ${ }^{6}$

\footnotetext{
4 Conforme a Lei 10.746 (artigo 4으, $\S 3^{\circ}$ ) que disciplina o acesso aos recursos do Fundo.

5 Criado pela Lei $10.201(14 / 02 / 2001)$.

6 Para uma avaliação sobre as propostas do Plano, sobre as dificuldades político-burocráticas encontradas para a implementação de suas ações e sobre os resultados alcançados, ver: Adorno (2003).
} 
Em 2003, o Projeto de Segurança Pública para o Brasil começa a ser implementado. Entre as suas propostas, destacam-se: a normatização do Sistema Único de Segurança Pública (Susp); a instalação, no estados, dos Gabinetes de Gestão Integrada de Segurança Pública; a integração territorial com a criação de AISPs (Áreas Integradas de Segurança Pública) em nível estadual; a "desconstitucionalização" das polícias; ${ }^{7}$ o foco na capacitação e valorização profissional das polícias; a ênfase na integração do conhecimento e no compartilhamento das informações; o estímulo às penas alternativas; o suporte aos mecanismos de controle das polícias através de ouvidorias e corregedorias unificadas; o tratamento específico da violência doméstica e de gênero, assim como aquela dirigida contra as minorias (crianças e adolescentes; idosos; negros; homossexuais); o investimento em políticas preventivas, no policiamento comunitário e na atuação das Guardas Municipais.

O que está listado acima são apenas alguns pontos de um Projeto marcado pela amplitude e profundidade no encaminhamento dos problemas levantados. Este Projeto estabelece um roteiro das questões a serem enfrentadas e que, de uma maneira ou de outra, vem servindo como um norteador das políticas indutivas propostas pelo governo federal, no âmbito da Senasp, desde então. ${ }^{8}$

Todavia, devemos nos ater com mais acuidade às reformas propostas na esfera municipal. Neste Projeto, a temática da segurança municipal já é merecedora de um tratamento (um capítulo) à parte (o que por si mesmo é significativo de como o tema da segurança municipal vem se desenvolvendo nos instrumentos programáticos governamentais), muito embora o foco esteja situado quase que exclusivamente no protagonismo das Guardas Municipais. Estas seriam as "gestoras e operadoras" da segurança pública em nível local, sem descuidar de sua articulação com as polícias estaduais e com as políticas integradas propostas no âmbito do Susp. À preocupação com a criação de uma identidade institucional e com a definição de um plano de cargos e salários, cuja mobilidade e hierarquia estariam baseadas em critérios meritocráticos, juntam-se projeções sobre a existência de núcleos de tratamento da informação e de gestão, de mecanismos de capacitação continuada e controle; prevendo-se, por fim, ao término dos vintes tópicos

\footnotetext{
7 Transferindo para os estados a tarefa de prever, em seus respectivos diplomas legais, o modelo policial apropriado - o que poderia resultar na unificação das polícias estaduais, assim como a criação de "polícias municipais" ou "metropolitanas" encarregadas tanto da investigação quanto do patrulhamento ostensivo uniformizado - denominadas "polícias de ciclo completo".

8 Para uma avaliação crítica do projeto de segurança pública para o Brasil, ver: Soares (2007).
} 
listados no capítulo, a concessão do "poder de polícia" para as guardas municipais que efetivarem as mudanças estruturais ali esboçadas.

Assim, algumas características presentes nesse documento saltam aos olhos, especialmente no que se refere ao nosso tema de interesse - a segurança municipal. Em primeiro lugar, a direção imprimida aos esforços de reforma - de cima para baixo, se podemos dizer assim, sem considerar as próprias Guardas Municipais e suas experiências acumuladas como parte da realidade local que se busca transformar. Em segundo - e é um tema que vamos explorar mais adiante - a redução da problemática da segurança pública "às modalidades da violência que se manifestam sob a forma de criminalidade" (p. 4). O terceiro ponto diz respeito à concessão de um "poder de polícia", que desloca as Guardas Municipais, talvez, de sua principal vocação (e que, paradoxalmente, é evocada no mesmo documento através da expressão "solucionadores de problemas" (p. 49). Em nosso entendimento, deveria se tratar, ao inverso, de confirmar sua vocação como agentes de um trabalho de prevenção que, sem poder fazer uso do "poder da polícia", ${ }^{9}$ afirma os processos de mediação e negociação de conflitos. E, por fim, a visão estreita que reduz os problemas de segurança nos municípios à atuação das Guardas (embora, talvez seja prudente ressaltar, até mesmo para evitar mal-entendidos, que tais instituições são atores proeminentes que devem ter sua atuação valorizada e otimizada através da adoção de medidas pertinentes). ${ }^{10}$

No ano de 2007, o governo federal lançou o Programa Nacional de Segurança Pública com Cidadania (Pronasci). E, novamente, aqui, temos uma linha de continuidade que atravessa os sucessivos planos e programas e que vem consolidando uma série de princípios. São eles: a integração intergovernamental (entre a União, Estados e Municípios; entre os poderes Legislativo, Executivo e Judiciário); a gestão intersetorial de projetos (com a participação em cada ente federado de diversos ministérios ou secretarias); o recurso às abordagens interdisciplinares (aqui parte-se do pressuposto de

\footnotetext{
Neste caso, trata-se de conferir às Guardas Municipais o "poder da polícia", no que diz respeito ao emprego coercitivo da força física ou letal. A expressão "poder de polícia" é inadequada, nesse caso, porque nos remete ao poder discricionário de todo e qualquer agente público, no exercício de sua função, para fazer valer o que está na lei. Sobre esse assunto, ver: Kant de Lima (1995, p. 119-125).

10 São vários os mecanismos de intervenção municipal na área de segurança: implantação de serviços de ouvidoria e disque-denúncia; monitoramento eletrônico dos espaços públicos; conselhos comunitários; conselhos tutelares; guardas municipais; secretarias municipais de segurança; gabinetes de gestão integrada municipais; fiscais de posturas; serviços de defesa civil, saúde, educação, esporte, lazer e infra-estrutura que concorrem para o desenvolvimento de mecanismos formais e informais de prevenção à violência e administração institucional de conflitos.
} 
que a criminalidade e a insegurança são fenômenos complexos e que, portanto, demandam abordagens múltiplas e diversificadas); a participação comunitária (que busca integrar os organismos da sociedade civil nos esforços de planejamento e execução de programas preventivos); a inserção local (considerando que as dinâmicas criminais ou conflitivas só podem ser compreendidas e abordadas a partir do contexto local); a prevenção situacional (que implica no redesenho do espaço urbano e na melhoria dos serviços de infra-estrutura); a prevenção social (baseada no entendimento de que as causas e as dinâmicas criminais estão associadas a fenômenos sociais abrangentes: educação, saúde, cultura, economia etc.).

Tais princípios, por sua vez, se sustentam sobre alguns valores que estão se tornando consensuais: prevenção não se opõe à repressão (são atividades complementares); as polícias têm um papel significativo a desempenhar na prevenção; a repressão policial qualificada deve estar em sintonia com a garantia e o respeito aos Direitos Humanos; as causas da criminalidade possuem "raízes sócio-culturais". Neste último caso estamos diante de um conjunto de fatores que respondem pelo desgaste da auto-estima; pela baixa qualidade de vida; pelo não reconhecimento da cidadania; pela ausência de um tratamento igualitário no acesso aos bens e serviços públicos. ${ }^{11}$

Assim, o Pronasci prevê 94 ações, a serem desenvolvidas até 2012. Neste Programa, o enfoque das ações está estabelecido de forma clara: a necessidade de se ter uma política específica para as polícias e para o sistema penitenciário; a atenção à juventude (com programas especialmente dirigidos aos jovens em situação de risco infracional ou criminal, como o "mães da paz"); o foco territorial nas regiões periféricas (especialmente das onze regiões metropolitanas mais violentas do país); a promoção dos Direitos Humanos através do reconhecimento da diversidade cultural e social (de gênero, étnica, de orientação sexual etc.).

No caso específico de São Gonçalo, os investimentos, tanto do PAC (Programa de Aceleração do Crescimento), quanto aqueles previstos no Pronasci (Programa Nacional de Segurança Pública com Cidadania), estão sendo endereçados para duas regiões consideradas carentes de investimentos

\footnotetext{
${ }^{11}$ A noção de "raízes sócio-culturais" do crime posiciona-nos diante do debate sobre as causas da criminalidade e especialmente aquela associada às camadas pobres da população. Não é nosso interesse desenvolver aqui essa discussão, apenas gostaríamos de ressaltar que esta noção aponta para um deslocamento de perspectiva significativo: que, se a pobreza não é a principal causa da criminalidade, a privação relativa não deixa de ser um fator causal importante, especialmente no que diz respeito à proliferação de conflitos interpessoais (para um exame detalhado desse assunto, ver: Misse, 2006, p. 3 -28).
} 
sociais e problemáticas em termos da segurança pública - "Jardim Catarina" e "Complexo do Salgueiro", firmando o critério territorial (muito em razão da articulação política com o PAC) o carro-chefe das primeiras ações do Pronasci. ${ }^{12}$

É importante ainda ressaltar que estes princípios que hoje informam os Planos e Programas na área de segurança pública e que, consequentemente, definem a direção das políticas indutivas implementadas pelo governo federal, constituem-se através do diálogo com uma série de perspectivas teóricometodológicas e modelos para "gerenciar a insegurança" (Silva, 2008, p. 228). Isto não é sem razão, se considerarmos as dezenas de colóquios organizados pelo Ministério da Justiça com diferentes atores sociais - promotores, juízes, defensores públicos, policiais, intelectuais, parlamentares etc. - quando da formulação do Pronasci (Abramovay e Paiva, 2007, p. 1). Assim, Azevedo e Fagundes apontam a existência, atualmente, de "um importante acervo de pesquisas (...) que permitem avançar em algumas conclusões sobre os caminhos a serem trilhados (...)" (2007, p. 90), especialmente considerando "a presença cada vez mais constante dos governos municipais no combate e na prevenção à violência e à criminalidade" (p. 91). ${ }^{13}$

Desta maneira, é importante não perder de vista a articulação entre as agendas políticas de intervenção social (considerando os documentos programáticos, a legislação pertinente à efetuação desses programas, o conjunto de instituições envolvidas) e os esforços na constituição de teorias criminológicas ou de modelos de atuação. Até mesmo para relativizar a nossa posição no campo da produção do conhecimento frente às demandas que hoje se colocam para os centros de pesquisa e para as universidades (públicas e privadas). A produção de um diagnóstico de segurança pública deve levar em conta esses fatores, articulando-os com a realidade local que está sendo pesquisada. Afinal, os objetivos e metas estabelecidos no Pronasci - e, como vimos, nos Planos que o antecedem - servem como diretrizes a serem consideradas durante o trabalho de campo, mas não podem ser tomados como um modelo dos resultados a serem alcançados ao término da

\footnotetext{
${ }^{12} \mathrm{O}$ tema da construção do pertencimento local, fundamental para a discussão e avaliação dessas ações, será examinado adiante.

${ }^{13}$ Neste artigo, os autores fazem uma breve apresentação, elucidativa em muitos aspectos, de como tais temas vem se constituindo no pensamento social. É interessante perceber aí que o modelo da "nova prevenção" (Dias Neto, apud Azevedo e Fagundes, 2007) coincide, na maioria de suas proposições, com os princípios presentes no PRONASCI: interpretação interdisciplinar; reavaliação da função policial; interagencialidade das políticas públicas de segurança; prevenção situacional; participação da sociedade civil; reconhecimento da pluralidade de grupos, interesses e demandas específicas; valorização do espaço local; presença do governo local.
} 
pesquisa. O que procuramos considerar aqui, levando em conta as demandas sugeridas pela administração pública municipal foi, efetivamente, compor uma interlocução com os representantes da sociedade civil e com as agências governamentais (federais, estaduais e municipais), que atuam em nível local, para a identificação dos problemas e possíveis soluções.

\section{O papel dos municípios na administração de conflitos}

Como ressaltamos anteriormente, ao falar do tratamento dado à segurança municipal no Plano de Segurança Pública para o Brasil, a ênfase é posta no combate às modalidades de violência associadas à criminalidade. Sem desmerecer a importância das ações qualificadas de repressão ao crime, todavia, devemos nos questionar em que medida essa ênfase não é representativa da maneira pela qual os conflitos são percebidos e tratados na sociedade brasileira. Em uma sociedade hierarquizada e excludente como a nossa, em que os diferentes segmentos sociais têm acesso particularizado a diferentes direitos e deveres, os conflitos são representados como perturbadores da ordem pública e não - como no caso das sociedades individualistas e igualitárias - criadores dessa mesma ordem, quando da explicitação da divergência de interesses entre iguais (Kant de Lima, 1996, p. 167). No caso brasileiro, os conflitos devem ser previamente abafados ou forçosamente conciliados, uma vez que sua explicitação revela a estrutura desigual da sociedade, onde conflitos de interesse entre desiguais são basicamente casos de polícia e não de justiça. Sinteticamente, nossa maneira de administrar os conflitos se caracteriza da seguinte maneira:

(...) exterioridade [com a intervenção constante de um Estado concebido acima da sociedade], pela generalidade [aplicação de uma norma geral], pela particularidade de sua aplicação [de acordo com as diferentes pessoas, situações e categorias sociais] e pela autoridade da interpretação" [o Estado ou os magistrados] (Kant de Lima, 1996, p. 170).

A inversão desse modelo, do nosso ponto de vista, passa, entre outras ações, pelo reconhecimento de que o município não é o protagonista das ações de repressão ou combate ao crime. Este é o papel das polícias estaduais e federais, assim como dos órgãos que compõem o sistema de justiça criminal. O município tem um papel a desempenhar que é complementar, em algumas situações, a tais estratégias de repressão qualificada, mas que não se confunde com elas. Sua atuação, na área de segurança pública, diz respeito diretamente à identificação e administração dos conflitos de acordo 
com a sua natureza, sua especificidade, à redução dos "riscos" e à promoção da civilidade.

No que diz respeito à identificação da natureza dos conflitos e sua administração institucional, cabe ao município desenvolver ações no sentido de romper com o modelo de controle social em que a informação é apropriada de forma particularizada. ${ }^{14}$ Para isso, além de criar um sistema de informações que possa, ao mesmo tempo, produzir e tratar estaticamente as informações recolhidas, a municipalidade deve investir na criação de mecanismos que facultem o diálogo com a sociedade civil organizada e a população em geral, quando do planejamento e da implementação de suas ações. Deve, igualmente, realizar campanhas de esclarecimento junto à população no que diz respeito ao exercício dos seus direitos e aos benefícios obtidos quando da explicitação das regras e de sua aplicação, promovendo, assim, a civilidade no espaço público. Isto no que se refere às inúmeras dimensões da vida social: comportamento no trânsito; educação ambiental; cuidado com os equipamentos públicos, etc. Cabe ainda à administração municipal tratar de coisas aparentemente simples, mas essenciais para administrar os conflitos existentes, tais como: investir em parcerias que permitam a todos os munícipes terem acesso ao saneamento básico, ao fornecimento de água, de luz e de transporte; melhorar os serviços na área de educação e na área da saúde; investir na construção de espaços direcionados à prática de atividades de lazer e esporte; incentivar as atividades culturais, e promover o acesso a tantos outros serviços públicos essenciais a uma vida com qualidade. Por fim, suas ações devem ser direcionadas considerando a especificidade das políticas de redução de risco - no trânsito, nas escolas, na área da saúde, nas ações que envolvem impacto ambiental, uso e abuso de drogas lícitas e ilícitas, dentre outras - elucidando sobre as maneiras mais adequadas das pessoas exercerem suas atividades com o menor risco para si mesmas, para o meio-ambiente e para a sociedade em que vivem.

Embora as ações da administração municipal possam ser consideradas ações propositivas ou diretivas, estas não devem reafirmar o caráter de exterioridade (e superioridade) da intervenção governamental, como assinalado acima, ao mencionarmos a forma como o conflito é administrado,

\footnotetext{
${ }^{14}$ Sobre este ponto, ressalta Kant de Lima: "[No Brasil] o domínio do público - seja moral, intelectual ou até mesmo o espaço físico - é o lugar controlado pelo Estado, de acordo com "suas" regras, de difícil acesso e, portanto, onde tudo é possivelmente permitido, até que seja proibido pela "autoridade", que detém não só o conhecimento do conteúdo mas, principalmente, a competência para a interpretação correta da aplicação particularizada das prescrições gerais, sempre realizada através de formas implícitas e de acesso privilegiado" (2008, p. 166).
} 
tradicionalmente, no Brasil. Desta maneira, devemos considerar, na construção de nossas abordagens e políticas públicas na área de segurança, o conjunto de representações acionadas pelos diversos atores e que orientam suas práticas, como o relato dos moradores que, quando deparados com situações "criminais" específicas, recusam admitir a necessidade da presença da polícia, ou, ainda, de interpretar alguns eventos como crimes, ao contrário do exposto no Código Penal Brasileiro.

No primeiro caso, ouvimos ao longo do trabalho de campo, depoimentos como esses: "conflitos em beira de praia se resolve na base do cacete"; "nossos conflitos a gente resolve aqui mesmo"; "não temos problema com o tráfico aqui. Qualquer pequeno problema do tipo, os moradores resolvem". Ou outras assertivas, ditas de forma velada, como as que se referem a assaltos ou roubos: "os caras dão um jeito nos ladrões". No que diz respeito ao segundo, podemos exemplificar com a fala de um dos presidentes de associação de moradores de São Gonçalo: "em briga de marido e mulher, não se mete a colher".

Em resumo, o tratamento dos conflitos envolve a identificação em sua particularidade, das razões pelas quais o conflito se desenvolve e de como pode se articular com outras situações conflituosas ou mesmo originá-las, assim como, a partir desse diagnóstico, a adoção de estratégias e mecanismos de intervenção que permitam a administração dessas situações, sem fazer uso de modelos repressivos orientados para a repressão criminal.

A seguir, vamos desenvolver essa discussão através do exame de um caso específico, o da violência doméstica no município de São Gonçalo.

\section{Espaços institucionais de prestação de serviços e atendimento à mulheres do município de São Gonçalo}

São Gonçalo é um dos dezesseis municípios que compõem a Região Metropolitana do estado do Rio de Janeiro. Situado à $20 \mathrm{~km}$ da capital e com uma população estimada em mais de um milhão de habitantes, o município dispõe de múltiplos espaços institucionais direta ou indiretamente relacionados à defesa dos direitos da mulher. Estes espaços, organizados por representações do poder público e/ou da sociedade civil organizada, compõem, em conjunto, uma das mais destacadas "redes de proteção social" atuantes na cidade e tem, entre suas entidades constitutivas, a Secretaria Municipal de Desenvolvimento Social, o Conselho Municipal de Direitos da Mulher, a Coordenadoria de Direitos da Mulher, os Conselhos de Assistência Social, a Secretaria de Integração, Defesa do Consumidor e Políticas para as Mulheres, a Rede Mulher, o Centro Especial de Orientação à Mulher e o Movimento de Mulheres em São Gonçalo. 
Conforme se depreende da pesquisa realizada no município, São Gonçalo apresenta uma série de problemas na área de segurança pública, dentre os quais destacam-se os casos de violência doméstica, especialmente os relativos à vítimas do sexo feminino. De acordo com dados do Instituto de Segurança Pública (ISP) do Rio de Janeiro referentes a 2006 e o primeiro semestre de 2007, o município figura entre os primeiros lugares no ranking estadual dos crimes cometidos contra a mulher, sendo que apenas os casos de ameaça registrados totalizaram 2.657 ocorrências no ano de 2006, levando São Gonçalo à segunda posição no ranking estadual, e 1.617 ocorrências no ano de 2007, o que manteve o município na segunda colocação em relação a essa modalidade específica de crime. Quanto aos casos de estupro, foram registradas 84 ocorrências no ano de 2006 e 37 no ano de 2007, o que colocou o município, respectivamente, em terceiro e quarto lugares no ranking estadual. Já os registros de atentado violento ao pudor totalizaram, consecutivamente, 56 e 39 ocorrências nos anos de 2006 e 2007, elevando São Gonçalo à sétima e terceira posições no ranking estadual, respectivamente, enquanto os crimes de lesão corporal registrados totalizaram 2.529 ocorrências no ano de 2006, pondo, assim, o município na segunda posição no ranking estadual, e 1.430 ocorrências no ano de 2007, o que o erigiu à terceira colocação, no referido período. Por fim, quanto aos casos de homicídio doloso, foram registradas 23 ocorrências no ano de 2006 e 11 no ano de 2007, colocando São Gonçalo, respectivamente, em quarto e oitavo lugares, respectivamente, no ranking estadual. ${ }^{15}$

O que chama a atenção nesses casos é que: ameaça, lesão corporal dolosa, atentado violento ao pudor e estupro são crimes com alta incidência de proximidade entre o agressor e a vítima (seja relacionamento amoroso, sejam as relações de parentesco, amizade ou vizinhança). ${ }^{16}$ São ações criminais, então, em que a proximidade relacional e a convivência territorial

${ }^{15}$ Segundo policiais entrevistados, os homicídios são oriundos do tráfico de drogas, dos crimes passionais e das disputas envolvendo o transporte informal no município. Não existem dados quantitativos, entretanto, que permitam uma avaliação mais rigorosa do assunto. Quanto ao tráfico de drogas, segundo os entrevistados o município se caracteriza pelos seguintes fatores: 1) não há disputas de territórios por facções rivais do tráfico; 2) o tráfico de São Gonçalo não tem grande poderio armado; 3 ) o tráfico é caracterizado pela venda do crack para a população de baixo poder aquisitivo; 4) o tráfico é um tópico central na criminalidade da região porque administra, ao seu modo, grande parte dos conflitos nas comunidades de baixa renda onde está instalado.

${ }^{16}$ É grande a subnotificação desses tipos criminais. Por vários motivos: medo de denunciar; a impossibilidade de deixar de conviver com o agressor; a falta de materialidade dos casos de atentado violento ao pudor etc. Entretanto, houve um aumento do número de registros dos tipos criminais que envolvem a violência contra a mulher em razão da criação da lei Maria da Penha e das campanhas que estimularam o registro. 
são componentes fundamentais a serem considerados quando do exame de sua natureza. Devemos ainda ressaltar que os conflitos que estão na origem desses crimes, se fossem administrados no devido tempo, poderiam ter sido encaminhados sem a criminalização dos autores e o sofrimento das vítimas.

Desta maneira, a gravidade do quadro apresentado tem suscitado, em âmbito local, a construção de diferentes espaços formais a partir dos quais a sociedade civil apresenta suas demandas, críticas e sugestões na área da segurança pública. Tratam-se tais espaços, fundamentalmente, de instituições e canais de reivindicação dos direitos da mulher cuja estruturação tem se baseado, nos últimos anos, tanto em iniciativas do poder público (sobretudo o municipal), como da sociedade civil organizada. Um importante espaço a ser destacado, nesse sentido, é o Movimento de Mulheres em São Gonçalo (MMSG) que, conforme sua apresentação formal, constitui-se em uma "entidade organizada da sociedade civil", fundada em 1989 e legalizada em 1991, auto-caracterizada como "uma entidade sem fins lucrativos, de utilidade pública municipal e estadual, inscrita nos Conselhos Municipais de Assistência Social e de Direitos da Criança e do Adolescente de SG". Atualmente, o quadro de associadas do MMSG é de, aproximadamente, duzentos e cinqüenta mulheres. A sua equipe técnica é composta de um advogado, uma educadora, três psicólogos, três assistentes sociais, além de inúmeros voluntários. ${ }^{17} \mathrm{~A}$ coordenação do movimento compete a uma diretoria colegiada formada por dez integrantes, cujas ações estão voltadas para as áreas executiva, administrativa, financeira, sócio-cultural, de divulgação e mobilização, além do conselho fiscal. Com grande inserção no município, a entidade tem assento nos Conselhos Municipais de Direito da Mulher, Assistência Social e da Criança e do Adolescente, sendo afiliada, ainda, à Rede Mulher de São Gonçalo.

Dentre os diversos objetivos do MMSG, destacam-se "a luta em defesa dos direitos das mulheres e contra todas as desigualdades e discriminações decorrentes do sexo, raça/etnia, credo religioso e classe social" e a "formulação de políticas públicas com abordagem de gênero e por serviços públicos que garantam o atendimento efetivo e continuado nas áreas da saúde, habitação, assistência social, emprego e renda, educação não diferenciada, acesso à

\footnotetext{
${ }^{17}$ Os "voluntários" são pessoas que se incorporam ao MMSG motivadas, inicialmente, pela participação em uma de suas reuniões. Conforme asseverou um entrevistado, muitos se interessam em fazer parte da ONG devido à oportunidade de ali obterem esclarecimentos e orientações (principalmente jurídicas) que, em geral, não lhes são acessíveis.
} 
justiça, meio ambiente, cultura, esporte e de lazer". Como parte de suas atividades, a entidade promove encontros, seminários, debates e reuniões sobre diversos temas relacionados aos direitos sociais e à agenda social.

Ao que nos interessa aqui, um dado relevante acerca da dinâmica de funcionamento do MMSG é o seu envolvimento em casos considerados "graves", nos quais, nas palavras de um entrevistado, "a polícia não resolve" os problemas. A esse respeito, o trabalho de campo atestou que há casos nos quais, a despeito da existência de demanda formal, os representantes da ONG vão ao encontro de "vítimas de violência doméstica", prontificando-se a participar dos processos investigativos, prestar assistência jurídica gratuita e intervir pessoalmente junto a atores do mundo político e do sistema judiciário, a fim de "sensibilizá-los" para as causas em questão ${ }^{18}$. De acordo com uma integrante do MMSG, este seria um recurso necessário para garantir agilidade e eficiência ao tratamento de tais casos, posto que, segundo ela, o funcionamento e o atendimento das demandas dirigidas às secretarias e demais órgãos públicos de segurança estão estreitamente vinculados à redes de relações pessoais estabelecidas entre os agentes de defesa dos direitos da mulher e os representantes das referidas instituições. Demonstrando conhecer bem a lógica personalista da sociedade brasileira, a entrevistada foi pragmática ao admitir que, no seu ofício, "a pessoalidade é tudo!".

Conforme foi possível depreender da pesquisa, longe de se tratar de uma manifestação isolada, essa postura reflete, de forma pontual e didática, uma percepção social mais ampla acerca de como devem ser preferencialmente encaminhadas as demandas sociais e, principalmente, de como elas são tratadas pelo Poder Público, especialmente no que tange à esfera municipal. Como deixa ver o discurso acima, as relações pessoais atravessam todas as esferas de atuação política, chegando mesmo a ser naturalizadas como uma espécie de mal necessário e inelutável. De acordo com o relato de um outro entrevistado, a lógica personalista (e, muitas vezes, clientelista!) estaria tão presente na distribuição de benefícios e serviços prestados pelos órgãos públicos municipais, que tornou-se, por fim, uma espécie de pré-condição obrigatória para o encaminhamento das causas sociais, não havendo, portanto, porque disfarçá-la ou escondê-la de quem quer que seja, inclusive

\footnotetext{
${ }^{18}$ Exemplar, nesse sentido, foi o caso de uma jovem gonçalense supostamente assassinada por seu ex-noivo, no ano de 2007, em que uma integrante do MMSG, valendo-se da proximidade pessoal, empregou o recurso de sensibilização junto a um delegado de polícia da região, fazendo-o, segundo ela, retificar o Registro de Ocorrência.
} 
dos pesquisadores. Segundo nos foi relatado, “os bairros onde a população é mais organizada nas suas reivindicações são aqueles que, de alguma forma, são atendidos pela prefeitura, mesmo que seja no esquema 'amigo de político". Dizem os entrevistados, quase em uníssono, se o "bairro é a base eleitoral ou curral eleitoral" de um determinado político, é de praxe que o mesmo dedique uma atenção especial e diferenciada a seus problemas.

Assim, esta discussão nos posiciona diante das imbricações entre a política local e as malhas de relações pessoais que são mobilizadas na efetuação dessa mesma política. Examinemos, de um ponto de vista mais amplo, os elementos que estão em jogo.

\section{Política e relações pessoais}

Como bem sabemos, recorrer às relações pessoais é uma prática muito difundida no Brasil. A prática é tão recorrente que, apesar de resultar de disposições socialmente adquiridas através de lições quase cotidianas, chegase mesmo a concebê-la como algo natural, que existe per si (Bezerra, 1995). Evidentemente, o recurso a tal prática não é exclusivo dos brasileiros, uma vez que, conforme observa DaMatta (1985), as redes de relações pessoais são universais. O que chama a atenção, contudo, no caso brasileiro é, conforme ressalta o antropólogo, o fato de que "elas sejam institucionalizadas, isto é, que tais redes sejam instrumentos conscientes e positivamente valorizados de navegação ou estratégia social" (p. 68). Segundo DaMatta, este fenômeno seria próprio de sociedades onde convivem éticas diferenciadas, como é o caso da sociedade brasileira. Nesse caso, por conta de uma complexa coincidência sócio-histórica, teríamos aprendido a lidar com duas éticas uma individualista e outra holista -, que operam em complementaridade, de modo que, de acordo com a conveniência, ora lançamos mão das regras e leis constitucionais que caracterizam as coletividades modernas, ora daquelas que governam a reciprocidade, a hospitalidade, a lealdade e a amizade.

Admite-se, assim, que as instituições sociais brasileiras estão sempre sujeitas a duas modalidades de pressão. Uma delas, típica da nossa vertente individualista, é a pressão universalista, "que vem das normas burocráticas e legais que definem a própria existência da agência como um serviço público". A outra, mais afinada com a lógica holista, seria "determinada pelas redes de relações pessoais a que todos estão submetidos e aos recursos sociais que essas redes mobilizam e distribuem" (DaMatta, 1985, p. 70).

Concomitantemente à lógica burocrática que informa as leis e regulamentos públicos, existe, assim, uma lógica de lealdades relacionais 
que, como observa Da Matta, "não têm nenhum compromisso legal ou ideológico" (p. 73). É em consonância com essa perspectiva que se torna possível entender a razão pela qual tanto a representante do MMSG (como, de resto, vários outros entrevistados, de instituições diversas) falam abertamente da maneira como mobilizam a atenção das autoridades públicas, ainda que eles afirmem que agem conforme as "regras do jogo", isto é, apresentam-se como cidadãos que, na legítima defesa de seus interesses e direitos, não vêem razão para esconder que, quando necessário, acionam todos os mecanismos institucionalmente disponíveis, sejam eles formais ou informais. Destarte, pode-se afirmar que, ao se valerem de seu prestígio pessoal, tais agentes procuram "efetivamente colocar à disposição de outras pessoas suas redes de relações pessoais, fazendo com que todas as instituições sociais possam subitamente se tornar eficientes" (DaMatta, 1985, p. 70).

Conforme deixam ver os discursos dos entrevistados, as relações pessoais constituem um recurso amplamente empregado por diferentes agentes, direta ou indiretamente envolvidos com o poder público, para lidar com os trâmites burocráticos ou, melhor dizendo, para contornar a rigidez e o formalismo da organização burocrática que se lhes impõe. Como, recorrentemente, o sistema burocrático apresenta uma série de exigências (muitas vezes incompatíveis umas com as outras), os indivíduos tendem a se valer de suas redes de relações e conhecimento pessoal para obterem os fins pretendidos ou, ainda, para simplesmente agilizarem a sua obtenção. Dessa maneira, para sobreviver dentro do sistema formalmente estabelecido, a solução encontrada parte de pressupostos opostos aos que norteiam a burocracia, de tal modo que, diante das exigências do poder público - que se pretende racional, impessoal e anônimo -, os agentes lançam mão de múltiplas estratégias que lhes permitem estabelecer um espaço pessoal naquele que, por definição, seria o domínio do impessoal. Nesse sentido, poder contar com um "delegado", "juiz" ou "vereador amigo" ou ter "conhecidos" nas várias esferas da administração municipal, constituem elementos de hierarquização capazes de garantir aos indivíduos e grupos o pronto atendimento de suas demandas em detrimento das demais que, pelo contrário, ficam ignoradas pelas autoridades públicas.

Com essas observações pretende-se assinalar que, na luta pela defesa de interesses e direitos, em São Gonçalo, não manter relações com pessoas que ocupam posições institucionalmente estratégicas "é algo considerado como altamente negativo, revelando apenas a solidão de alguém que, sem ter vínculos, é um ser humano marginal em relação aos outros membros da comunidade" (DaMatta, 1985, p. 65). Por essa razão, entre outras, na 
contramão do que propõe a definição, digamos, ortodoxa de cidadania, deve-se levar em conta que, em contextos como o ora examinado, enquanto a invocação da lei universal resulta, não raro, na obtenção de respostas negativas aos demandantes (fundadas em argumentos gerais como carência de recursos, falta de pessoal, morosidade da lei etc.), por outro lado, pululam mecanismos alternativos que, segundo sua lógica própria, mostram-se fortemente influentes na definição dos critérios de distribuição dos bens e serviços públicos.

Isto posto, se nos é lícito supor que o estudo do caso de São Gonçalo pode contribuir em alguma medida para a compreensão da dinâmica que engendra as políticas públicas municipais brasileiras, especialmente as da área da segurança pública, há que se dizer que tal contribuição se deve, em boa medida, ao reconhecimento do caráter relacional que, a despeito do universalismo institucional e formalista, atravessa as ações do poder público. A reflexão sobre as imbricações, continuidades e descontinuidades existentes entre essas diferentes éticas constitui elemento obrigatório para o entendimento não só dos discursos apresentados mas, especialmente, das práticas derivadas do modo próprio de se conceber e efetuar políticas públicas no Brasil.

\section{Representações sobre o pertencimento local da violência}

Como mencionamos anteriormente, os programas federais têm enfatizado uma perspectiva de segurança pública mais abrangente, com ênfase na reformulação da formação policial, com um discurso voltado para o respeito aos direitos humanos e para uma mudança no papel dos municípios. Além da liberação de recursos para formação das Guardas Municipais e para compra de equipamentos de segurança, os investimentos recentes em diferentes municípios brasileiros, dentre eles São Gonçalo e Mesquita, voltam-se para reformas na infra-estrutura municipal, com obras de saneamento básico, construção de casas, etc. Há, por parte dos idealizadores desta política indutiva, um discurso de que é necessário investir na prevenção da violência, reduzindo assim os índices de criminalidade. Entretanto, é importante ressaltar que a escolha dos locais onde tais programas serão desenvolvidos está baseada em representações das autoridades ou técnicos municipais a respeito da violência deste ou daquele bairro, representação esta que nem sempre coincide com a dos moradores. Foi freqüente, ao longo da pesquisa, ouvirmos das pessoas entrevistadas que o seu bairro ou sua rua não são locais violentos, atribuindo a violência a um "outro", um bairro 
vizinho, um bairro distante, ou até mesmo a outros municípios que, por alguma razão pontual, teriam provocado o deslocamento de criminosos para o local onde residem. Mesmo as fronteiras entre os bairros não são explícitas, conforme a divisão estabelecida administrativamente pelas prefeituras. As fronteiras se "movem" segundo critérios específicos dos moradores, e os discursos acerca da violência dos bairros ou da criminalidade existente se deslocará segundo estes mesmos critérios.

Este deslocamento interfere diretamente no planejamento das políticas públicas de segurança, informadas por estatísticas criminais, por sua vez construídas a partir de recortes espaciais diversos daqueles adotados pelos habitantes locais. O planejamento da ação policial deve ocorrer, segundo a Secretaria de Segurança Pública do Estado, a partir das AISPs - Áreas Integradas de Segurança Pública. Cada AISP reúne locais de intervenção que devem fazer coincidir a circunscrição da Delegacia de Polícia Civil e do Batalhão de Polícia Militar. Não há, neste planejamento, nada que leve em consideração as representações locais que permeiam os municípios. Muito ao contrário, os municípios que compõem uma AISP podem ter características muito distintas, até mesmo no que se refere à natureza dos conflitos existentes. Todos estes fatores implicam em uma defasagem constante entre o planejamento das ações policiais e a demanda da população.

\section{O “deslocamento" dos bairros}

Uma das principais conseqüências da mobilidade das fronteiras entre bairros é o planejamento das políticas públicas, a começar pelo Plano Diretor, obrigatório para todos os municípios brasileiros. Um plano diretor tem, além do óbvio planejamento do espaço, a necessidade, segundo a legislação brasileira, de resultar da participação popular,e,portanto, supostamente, resultar de um acordo entre autoridades, técnicos e moradores, acerca dos limites do que seria necessário planejar, de onde e do que deve ser feito em termos de investimentos públicos. No entanto, se por um lado os técnicos querem preservar sua perspectiva acerca do espaço urbano, por outro, os moradores associam este espaço a valores muito diversos. É assim que, no município de São Gonçalo, conforme já demonstrou Guedes (1997) diferentemente dos limites precisos e operados pelas categorias município, distrito, bairro, utilizadas pelos técnicos, os moradores podem denominar São Gonçalo somente o centro administrativo da cidade, enquanto o seu lugar de moradia reduz-se ao seu próprio bairro. Esta representação é parte de um distanciamento proposto entre moradores e políticos; estes, muitas vezes marcados por sinais negativos, tais como a denominação de corruptos, 
ineficazes ou traidores dos interesses locais. Pode ainda representar para os moradores a diferença existente entre bairros sem qualquer, ou com pouca infra-estrutura (como rede de esgoto, calçamento, asfaltamento de ruas, fornecimento de água e luz) e um "centro" no qual estão presentes todos esses recursos:

(...) o termo São Gonçalo é usado, na maioria das vezes, na sua acepção político-administrativa, evocando as avaliações do governo, os problemas de infra-estrutura urbana vividos cotidianamente pelas pessoas e, mais raramente, o município, enquanto mercado de trabalho. Situar-se nesse mapa é referirse a uma esfera institucional de poder, externa a eles, mas relativamente próxima, tematizando, de modo específico - pela carência de equipamentos urbanos - a experiência da desigualdade social (...) (Guedes, 1977, p. 71).

Em Mesquita, num outro exemplo pertinente à discussão aqui proposta, a administração local não consegue avançar na construção de um "mapa" administrativo, com estabelecimento de limite entre bairros (o que denominam de "abairramento"), porque representantes das populações locais não chegam a um acordo com os técnicos municipais acerca dos limites e denominações dos bairros. Para exemplificar os problemas decorrentes dessas diferentes representações dos bairros, a Secretária de Saúde ressalta que as informações sobre "onde se mora" são do morador, pois "não há um mapa de bairros definido"; essa definição é particularmente difícil, segundo a Secretária, por se tratar de um município "pequeno do ponto de vista territorial", "as regiões são próximas, o que dificulta a definição". Nota-se que, para a secretária, a dificuldade está situada na informação que é dada diretamente pelo morador, o que impede que seja feito um mapeamento das doenças existentes, que só pode ser pensado a partir de critérios definidos oficialmente, visto que dois moradores supostamente residentes em um mesmo "bairro" ou em uma mesma "rua" podem se declarar de bairros ou ruas distintas, dificultando o planejamento das ações da Secretaria.

Mas, se por um lado, os técnicos apontam para a dificuldade de planejamento do seu trabalho, por conta das representações locais, por outro, os moradores utilizam o pertencimento a este ou aquele "bairro" para obtenção de recursos públicos, como é possível depreender do discurso de um dos presidentes de associação de moradores de Mesquita:

Este bairro não faz parte do bairro de Cosmorama. Cosmorama é um bairro vizinho, conhecido como o bairro mais rico do município, mas tem interesse em afirmar que a "comunidade" de Edson Passos faz parte da sua área, usando a pobreza da região 
para conseguir atenção e recursos. Eles não ganhariam nada porque são vistos como mais ricos. Por exemplo, um carro para desentupimento de bueiro foi enviado para o bairro vizinho, enquanto o Cosmorama não recebeu, mas foi um dos que mais sofreu com as enchentes.

Ao mesmo tempo em que podem utilizar representações da pobreza local, buscando um código comum com as representações municipais, para distribuição favorável de recursos, outras podem ser recusadas, como aquelas que atribuem classificações vistas como extremamente opostas aos valores dos habitantes locais. Este é o caso das representações sobre a violência local, que podem ser rejeitadas, ainda que aceitá-las possa significar o aporte de recursos significativos, como é o caso dos investimentos do Pronasci. Os moradores de São Gonçalo, por exemplo, reagiam favoravelmente quando alguém mencionava que os recursos que seriam aplicados ao seu bairro estavam ligados à ausência de infra-estrutura, como, por exemplo, saneamento básico, fornecimento de água, etc; entretanto, reagiam desfavoravelmente à relação entre a ausência de infra-estrutura e sua vinculação à violência ou à criminalidade local. Para os moradores de São Gonçalo, assim como os de Mesquita, a violência é do "outro": a outra rua, o outro bairro ou o município vizinho.

\section{O deslocamento da violência}

Guedes, no texto mencionado acima, já havia ressaltado como as denominações atribuídas a determinados locais podem significar um "sistema de classificação/diferenciação entre pessoas que, sob diversos pontos de vista, partilham, objetivamente, uma série de outras coisas" (1977, p. 94) e como esse sistema influencia no reconhecimento e na utilização do espaço urbano. Ao tentar localizar um local no município de São Gonçalo, denominado Coruja ou Buraco da Coruja, descobriu que sempre se tratava, no discurso dos moradores, de um local mais adiante, nunca localizado por ninguém. Suas fronteiras se ampliavam de acordo com o interlocutor, porque a Coruja, ou ao Buraco da Coruja, associavam-se características vistas como negativas pelos moradores locais. Tratava-se de um lugar representado no discurso dos moradores como um "local violento", "abrigo de bandidos", "um lugar barra pesada" (p. 96). Deste modo, "a Coruja pode estar aqui ou acolá, não se situando em lugar nenhum. (...) nenhuma das pessoas que conhecemos lá (...) diz morar no Buraco da Coruja. Sempre situada mais adiante (no terreno) ou mais atrás (no passado), a Coruja é, antes de tudo, a fronteira ameaçadoramente próxima, cercada de ambigüidade" (p. 99). 
Da mesma forma, foi possível, ao longo do trabalho de pesquisa, observar algumas estratégias dos moradores, ora em recusar as denominações dos bairros como forma de descartar a pecha de bairro violento, ora em reconhecer que era aquele o seu bairro, mas cuja violência era um equívoco do interlocutor, para em seguida atribuir ao "outro" qualquer sinal de violência ou criminalidade.

A primeira estratégia está presente no discurso de diferentes representantes de associações de moradores de Mesquita, e pode explicar o fato de não aceitarem o "mapa oficial" referido pela Secretária de Saúde. É o que podemos notar no discurso do Presidente da Associação de Moradores do bairro de Chatuba, classificado por diversos entrevistados como um bairro violento e com índices significativos de criminalidade:

Qualquer adensamento a nível de quarenta mil habitantes tem problemas sociais, principalmente na Baixada Fluminense, por causa da saúde, educação. (...) Mas aqui em Chatuba, os moradores têm o luxo de conviver com a vizinhança de portas abertas, as crianças brincam até tarde na rua, sem qualquer problema.

Comparando com o município do Rio de Janeiro, afirma: "os pontos críticos não são tão relevantes assim", e menciona a capa dos jornais que noticiam diariamente diversas notícias de violência e de crime no Rio de Janeiro: "em Chatuba não é assim".

$\mathrm{Ou}$, ainda, como no discurso do representante de uma das associações do Jardim Carolina, que estende a recusa a todo o município: "Mesquita vive um momento de paz, mas quando a coisa aperta lá embaixo [Rio de Janeiro] quem paga é a Baixada".

O mesmo se pode observar em São Gonçalo, quando atribuem as características de violência a um espaço quase contíguo, mas visto como diverso pelos moradores entrevistados. Elas fazem parte do cotidiano do "novo" Jardim Catarina, em oposição ao "velho", composto por moradores antigos, e onde a violência não é significativa. ${ }^{19}$ No discurso dos moradores, no Jardim Catarina "velho", não há tráfico, violência ou crimes significativos.

Esta interpretação do local violento a partir de categorias "velhos" e "novos" está presente também em Mesquita, no bairro de Chatuba, já mencionado:

Chatuba é um bairro tradicional, foi formado ao longo do tempo, as pessoas conhecem todo mundo e tem boa relação, ao contrário de um conjunto habitacional, que chegou todo mundo ao mesmo tempo.

\footnotetext{
${ }^{19}$ Para as implicações das classificações "velhos" e "novos" no contexto mencionado aqui, ver: Guedes (1997); Elias e Scotson (2000).
} 
Como adverte Guedes:

(...) quanto mais tempo, mais possibilidade de gerar relações sociais significativas, organizadas pelo seu agrupamento em famílias, pelo conhecimento que uns têm dos outros e do espaço no qual se situam. A falta de profundidade neste eixo implica numa apropriação do espaço puramente utilitária, associando-se a poluição (do espaço) à indiferença e possível violência (nas relações sociais) (1997, p. 60).

É importante notar que há, também nesses casos, o receio do "efeito contaminação". Por isso, muitos entrevistados situavam a violência para bem longe do seu bairro, ou para fora do seu município, como já foi descrito anteriormente.

Um último ponto a ser mencionado, é a diferença existente nos modelos de administração pública presentes nos dois municípios estudados. Essa diferença sugere o cuidado necessário para não tendermos a avaliar tais escolhas de forma maniqueísta, perdendo a riqueza que as diferentes interpretações dos moradores locais nos possibilitaram conhecer. Os dois modelos observados apontam para algumas questões relevantes, dentre outras, o fato de que a gestão participativa (adotado por Mesquita), é, no Brasil, uma obrigação dos municípios, estabelecida por legislação específica. ${ }^{20}$ Isto significa que, no mínimo, ela está marcada por um modelo de participação não necessariamente acordado pelos moradores dos municípios, visto que é previamente estabelecido. Por outro lado, um modelo marcado por relações pessoais, como o presente no município de São Gonçalo, pode indicar um modelo de gestão próximo àquele esperado pelos moradores locais, já que, conforme demonstrou Guedes, a desconfiança dos políticos ou de forma mais extensa, à política, se contrapõe na representação dos moradores, à confiança nas "pessoas", naquelas que podem representar seus valores construídos em pertencimentos locais (como os bairros, por exemplo).

\section{Conclusão}

Como propusemos na introdução, neste artigo procuramos desenvolver algumas reflexões sobre a segurança pública municipal, a partir do exame das ações indutivas do governo federal, da consideração da centralidade dos processos de administração de conflitos na condução das políticas públicas na área da segurança pública, assim como da apreciação do peso das malhas de relações pessoais na condução destas mesmas políticas e da relevância

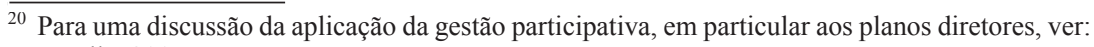
Varella, 2007.
} 
dos processos de construção dos pertencimentos locais. São apenas alguns temas entre os inúmeros suscitados quando da apreciação do assunto e que se fazem presentes na produção dos diagnósticos de segurança pública municipal. Assim, esperamos ter contribuído para o aprofundamento da discussão sobre a municipalização da segurança pública no Brasil.

\section{Referências}

ABRAMOVAY, P. V.; PAIVA, L. G. M. O programa nacional de segurança pública. Boletim do Ibccrim, 2007, n. 181, p. 1-3. Disponível em: <www.ibccrim.org.br>. Acesso em: 14 jul. 2008.

ADORNO, S. Lei e ordem no segundo governo FHC. Tempo Social, v. 15, n. 2, p. 1-21, 2003. Disponível em: <www.scielo.br>. Acesso em: 28 jul. 2008.

AZEVEDO, R. G.; FAGUNDES, A. L. A municipalização da segurança pública no Brasil: pressupostos teóricos e critérios para a implementação de políticas públicas de segurança. Revista de Estudos Criminais, n. 26, p. 89-106, 2007.

BEZERRA, M. O. Corrupção: um estudo sobre poder público e relações pessoais no Brasil. Rio de Janeiro: Relume-Dumará, 1995.

DAMATTA, Roberto. A casa e a rua: espaço, cidadania, mulher e morte no Brasil. São Paulo: Brasiliense, 1985.

ELIAS, N.; SCOTSON, J. L. Os estabelecidos e outsiders. Rio de Janeiro: Zahar Editores, 2000.

GUEDES, Simone Lahud. Jogo de corpo. Niterói: Eduff, 1997.

LIMA, Roberto Kant de. A polícia da cidade do Rio de Janeiro: seus dilemas e paradoxos. Rio de Janeiro: Forense, 1995.

. A administração dos conflitos no Brasil: a lógica da punição. In: ALVITO, M.; $\overline{\mathrm{VELHO}}$, G. (Org.). Cidadania e violência. Rio de Janeiro: Editora FGV, 1996.

. Ensaios de Antropologia e de Direito: acesso à justiça e processos institucionais de administração de conflitos e produção da verdade jurídica em uma perspectiva comparada. Rio de Janeiro: Lumen Juris, 2008.

MISSE, Michel. Crime e violência no Brasil contemporâneo: estudos de sociologia do crime e da violência urbana. Rio de Janeiro: Lumen Juris, 2006.

SILVA, Jorge da. Criminologia crítica: segurança pública e polícia. Rio de Janeiro: Forense, 2008.

SOARES, Luiz Eduardo. A política nacional de segurança pública: histórico, dilemas e perspectivas. Estudos Avançados, v. 21, n. 61, p. 2-15, 2007. Disponível em: <www. scielo.br>. Acesso em: 18 jul. 2008.

VARELLA, Alex. O dever de cidadania: políticas públicas de planejamento urbano e participação popular no Brasil. In: LIMA, Roberto Kant de et al. (Org.). Gestão em segurança pública e justiça criminal: reflexões sócio-antropológicas. Niterói: [s.d.], 2007. No prelo.

Recebido em: 7 ago. 2008 Aprovado em: 11 set. 2008 